\title{
Téoros
}

Revue de recherche en tourisme

\section{Le tourisme et les transports}

\section{Jean Stafford}

Volume 6, numéro 1, mars 1987

Tourisme et transports

URI : https://id.erudit.org/iderudit/1080515ar

DOI : https://doi.org/10.7202/1080515ar

Aller au sommaire du numéro

\section{Éditeur(s)}

Université du Québec à Montréal

ISSN

0712-8657 (imprimé)

1923-2705 (numérique)

Découvrir la revue

Citer ce document

Stafford, J. (1987). Le tourisme et les transports. Téoros, 6(1), 2-2.

https://doi.org/10.7202/1080515ar d'utilisation que vous pouvez consulter en ligne.

https://apropos.erudit.org/fr/usagers/politique-dutilisation/ 


\section{Présentation}

\section{Le tourisme et les transports}

La plupart du temps, le développement de l'industrie touristique est le fidèle reflet du développement de l'industrie des transports. A certains moments, mais rarement, c'est la demande touris tique qui mène le jeu; à d'autres moments, et le plus souvent, ce sont les nouvelles technologies des transports qui vont conditionner la demande touristique.

Ces remarques sont valables pour le Québec et ses voisins et dans I'optique où plusieurs modes de transport pourraient ètre concurrentiels. En considérant /'évolution des liens entre le tourisme et le transport on a l'impression que le transport forme l'infrastructure du système et le tourisme la superstructure.

Nous savons que dans la pensée marxiste ce sont les infrastructures qui dominent et imposent des solutions aux différents problèmes socio-économiques. Dans cette dialectique constante, le tourisme perçu comme culture, comme modèle, et même comme style de vie, est de plus en plus réduit à la portion congrue. Ce sont les impératifs technologiques qui dictent la forme des relations entre l'industrie du tourisme et celle des transports.

A la réflexion, cette domination n'a rien d'étonnant, rindustrie des transports, pour survive, accorde un röle déterminant au progrès technique, à l'efficacité des movens de production par le biais de constantes innovations, elle engage dans ce processus d'énormes investissements, pour elle c'est une question de vie ou de mort.

L'industrie touristique, au sens le plus large du terme, est un secteur mou de l'économie oủ les investissements sont faibles et ouे, habituellement, on accorde peu d'importance aux découvertes technologiques et au développement du "capital humain". Dans cette perspective, le tourisme peut difficilement résister aux ajustements constants imposés par le systeme des transports.

Cette domination n'est peut-être pas inéluctable et éternelle mais elle pèse actuellement d'un poids énorme sur toutes les stratégies de développement et de planification (surtout en milieu régional) touristiques.

La forte concurrence entre les moyens de transport tend à une réduction quasi-systématique des choix: depuis 1940 , le bateau et le train sont presque disparus comme modes de transport touristique. L'automobile semble plafonner et seuls l'autobus et l'avion ont une croissance constante. Les contraintes telles que les coûts, le temps et la sécurité mènent à une limitation des possibilités.

La limitation du choix des moyens de transport entraine aussi des restrictions au niveau du choix des destinations; par exemple, la longueur des pistes d'atterrissage va devenir une condition préalable à la venue de touristes. Donc, la réduction des moyens de transport va amener une réduction de l'espace et la valorisation mécanique de corridors touristiques aux dépens des autres destinations.

La diversite et l'efficacité des modes de transport sont de bons indicateurs de la santé du tourisme. L'excès de spécialisation du système de transport est un danger mortel pour l'industrie touristique québécoise. C'est donc aux intervenants touristiques de proposer, d'agencer certaines alternatives qui favoriseraient une utilisation optimale de plusieurs modes de transports.

Ce pluralisme des moyens de transport est vital pour le tourisme régional. // est aussi nécessaire pour les grandes viles; quand leurs attraits s'usent et vieillissent elles doivent alors s'appuyer sur l'arrière pays pour redevenir attractives. D'une façon ou d'une autre, /'avenir du transport est aussi /'avenir du tourisme et les defaites de l'un seront les défaites de l'autre $f$

Jean Stafford

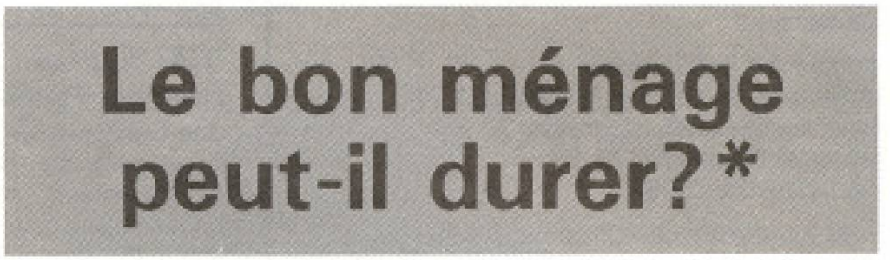

$\mathrm{Si}$, parce que les coûts augmentent, le touriste est amené à ménager ses transports, il doit encore et toujours se déplacer dans un espace géographique pour satisfaire la condition essentielle de l'expérience touristique. L'étude des moyens de transport reste donc un sujet privilégié pour traiter du tourisme.

En fait, nous pourrions écrire une bonne part de l'histoire et de l'évolution récente du tourisme en suivant les changements survenus dans les moyens de transport.

"Editorial collectif par l'equipe de rédaction de TÁoros: redigh par Mare Laplante, sociologue, Departement detudes urbaines, UQAM. 